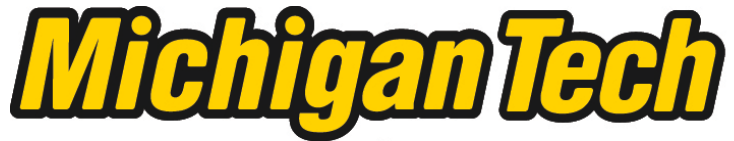 \\ Michigan Technological University Create the Future Digital Commons @ Michigan Tech
}

Dissertations, Master's Theses and Master's Reports - Open

Dissertations, Master's Theses and Master's

Reports

2010

\section{Golden-winged Warbler habitat model validation for northern Wisconsin and central Minnesota}

Alexandra E. Wrobel

Michigan Technological University

Follow this and additional works at: https://digitalcommons.mtu.edu/etds

Part of the Forest Sciences Commons

Copyright 2010 Alexandra E. Wrobel

\section{Recommended Citation}

Wrobel, Alexandra E., "Golden-winged Warbler habitat model validation for northern Wisconsin and central Minnesota", Master's Thesis, Michigan Technological University, 2010.

https://doi.org/10.37099/mtu.dc.etds/144

Follow this and additional works at: https://digitalcommons.mtu.edu/etds

8 Part of the Forest Sciences Commons 


\title{
GOLDEN-WINGED WARBLER HABITAT MODEL VALIDATION FOR NORTHERN WISCONSIN AND CENTRAL MINNESOTA
}

\section{By}

Alexandra E. Wrobel

\begin{abstract}
A THESIS
Submitted in Partial Fulfillment of the Requirements for the

degree of

MASTER OF SCIENCE IN APPLIED ECOLOGY
\end{abstract}

MICHIGAN TECHNOLOGICAL UNIVERSITY

2010 
This thesis, " Golden-winged Warbler Habitat Model Validation for Northern Wisconsin and Central Minnesota" is hereby approved in partial fulfillment of the requirements for the Degree of MASTER OF SCIENCE IN APPLIED ECOLOGY

School of Forest Resources and Environmental Science

Signatures:

Thesis Advisor

David J. Flaspohler

Dean

Margaret R. Gale

Date 


\section{Acknowledgements}

I would like to acknowledge contributions of these specific organizations and individuals who aided in the development of this thesis.

Thank you to my advisor David J. Flaspohler for both guidance and support. Thank you to Wayne Thogmartin of the U.S. Geological Survey for the creation of these population models and offering advice. My committee; Ann Maclean and Robert Froese from the School of Forest Resources and Environmental Science, and Robert Keen of the Department of Biological Sciences at Michigan Tech. I would like to give a big thank you to Amber M. Roth for making all of this possible.

Thank you to the U.S. Fish \& Wildlife Service, the School of Forest Resources and Environmental Science (SFRES) at Michigan Technological University and to the King Chavez Fellowship for making funds available. Thanks to Justin Gustafson for his work in the field and all of the federal agencies that allowed us access to their land.

A personal thank you to Elizabeth Boisvert, Lucas Spaete, Nicholas Jensen, Paul Koll and all of the other graduate students in the SFRES for all of their advice and moral support. And a special thanks to Jonathan Coyne for moral support and my parents Susan and Andrew Wrobel for moral support, advice and work in the field. 


\section{Abstract}

Between 1966 and 2003, the Golden-winged Warbler (Vermivora chrysoptera) experienced declines of $3.4 \%$ per year in large parts of the breeding range and has been identified by Partners in Flight as one of 28 land birds requiring expedient action to prevent its continued decline. It is currently being considered for listing under the Endangered Species Act. A major step in advancing our understanding of the status and habitat preferences of Golden-winged Warbler populations in the Upper Midwest was initiated by the publication of new predictive spatially explicit Golden-winged Warbler habitat models for the northern Midwest. Here, I use original data on observed Golden-winged Warbler abundances in Wisconsin and Minnesota to compare two population models: the hierarchical spatial count (HSC) model with the Habitat Suitability Index (HSI) model. I assessed how well the field data compared to the model predictions and found that within Wisconsin, the HSC model performed slightly better than the HSI model whereas both models performed relatively equally in Minnesota. For the HSC model, I found a 10\% error of commission in Wisconsin and a $24.2 \%$ error of commission for Minnesota. Similarly, the HSI model has a $23 \%$ error of commission in Minnesota; in Wisconsin due to limited areas where the HSI model predicted absences, there was incomplete data and I was unable to determine the error of commission for the HSI model. These are sites where the model predicted presences and the Golden-winged Warbler did not occur. To compare predicted abundance from the two models, a $3 \times 3$ contingency table was used. I found that when overlapped, the models do not complement one another in identifying Golden-winged Warbler presences. To calculate discrepancy between the models, the error of commission shows that the HSI model has only a $6.8 \%$ chance of correctly classifying absences in the HSC model. The HSC model has only $3.3 \%$ chance of correctly classifying absences in the HSI model. These findings highlight the importance of grasses for nesting, shrubs used for cover and foraging, and trees for song perches and foraging as key habitat characteristics for breeding territory occupancy by singing males. 


\section{Introduction}

Between 1994 and 2003, Golden-winged Warbler (Vermivora chrysoptera) populations in eastern North America declined by an average of $3.4 \%$ per year, with declines as high as $20.4 \%$ over this 9 -year period in some portions of their breeding range (Buehler et al. 2006). This has prompted national concern for the conservation of this long-distance migratory songbird. Along with these declines, during the last 37 years, the Golden-winged Warbler breeding range in the Midwestern U.S. has shifted to the northwest, increasing in parts of central Canada while disappearing from parts of the southern Appalachian Mountains (Figure 1). The reasons for these changes in population size and breeding distribution are not well understood. Possible mechanisms include hybridization with the Blue-winged Warbler (Vermivora pinus) (Gill 1997), habitat loss due to forest maturation, human land use change (Buehler et al. 2006), and climate change (Hands et al. 1989). Habitat changes on the wintering grounds in Central and South America may also be contributing to breeding population declines although little information is available on winter habitat use or abundance (Confer 1992).

To the extent that recent declines are related to habitat quality on the breeding grounds, conservation of existing high quality habitat and the improvement of areas of low quality or unsuitable habitat will be important steps 
in slowing the decline or facilitating the expansion of known populations (Barker Swarthout et al. 2009, Buehler et al. 2006). Breeding Golden-winged Warblers are associated with early successional forest/shrubland and shrubby wetland habitats. Territory size averages 1-2 ha and often includes dense herbs, grasses, and/or shrubs which help to conceal ground nests (Confer 1992). Typical breeding territories also contain scattered trees or forest edges used by males for song perches and for foraging (Confer 1992). In a previous study, Frech and Confer (1987) found that 10 of 12 Golden-winged Warbler territories included some type of forest opening such as areas of sedge or grass, mowed lawns, roads, or utility rights-of-way.

\section{Golden-winged Warbler Status in North America}

Historically, the Golden-winged Warbler bred from the Appalachian Mountains, north through central New England west to the northern Great Lakes states and southern Ontario and Manitoba. This range has changed dramatically in recent decades (Buehler et al. 2006). The USGS North American Breeding Bird Survey (BBS) data prior to 1994 showed a range-wide decline for Goldenwinged Warbler populations of approximately $2.4 \%$ per year. However populations were stable or increasing in the boreal-hardwood transition region of the upper Midwest (Figure 2) (Sauer et al. 2008). An analysis for 1994-2003 showed a $9.0 \%$ annual decline for some parts of U.S. Fish and Wildlife Service (USFWS) Region 3 (which includes the north-central states of Michigan, 
Wisconsin and Minnesota), and a 20.4\% decline in FWS Region 5 (Northeastern U.S.). Because populations were already so low during this period for FWS Region 4 (Southeastern U.S.), confidence in these trend data was reduced (Buehler et al. 2006).

Bird Conservation Region (BCR) 12 includes the northern hardwood and conifer transition area of northern portions of Wisconsin and Michigan, the north eastern portion of Minnesota, and some parts of southern Canada (Figure 3)(Sauer 2008). Of an estimated global population of $105,000-270,000$ breeding pairs of Golden-winged Warblers, recent data suggest that the Minnesota and Wisconsin portion of Bird Conservation Region (BCR) 12 may account for nearly $50 \%$ of the population (PIF 2007). Because of recent declines described above, the Golden-winged Warbler has been identified as a "Species of Greatest Conservation Need" in Minnesota's Comprehensive Wildlife Conservation strategy" (Stucker 2009), a priority species under the Wisconsin Bird Conservation Initiative, a species of "Special Concern" and a "Species of Greatest Conservation Need" by the Wisconsin Department of Natural Resources (http://dnr.wi.gov/org/land/er/WWAP/). It is also considered a species of concern under the authority of the USFWS as well as a species requiring immediate action by Partners in Flight (Rich et al. 2004, http://www.fws.gov/migratorybirds/). In February 2010, a petition was filed to list the Golden-winged Warbler as threatened or endangered under the Endangered Species Act (Will 2009). 
To address the habitat needs of the Golden-winged Warbler on the breeding grounds, it is essential to have a more detailed understanding of breeding habitat preferences. Golden-winged Warblers use a variety of early successional and open shrubland habitats for breeding although it is not clear how birds in different parts of the breeding range favor particular types of useable breeding habitat (Buehler et al. 2006). Federal and state land management agencies and non-profit organizations working to conserve the Golden-winged Warbler need a better understanding of how Golden-winged Warblers are distributed during the breeding season in the core of their breeding range. This information can then be used to direct conservation efforts.

To aid in this effort, Thogmartin developed predictive population abundance models for the Golden-winged Warbler that sought to identify suitable breeding habitat in northern Wisconsin and Minnesota (Thogmartin and Knutson 2007). Two models were created and are known as the Hierarchical Spatial Count (HSC) and the Habitat Suitability Index (HSI). The goal of these models was to provide testable predictive models of species occurrence during the breeding season based on existing data.

Such population models have become increasingly important in ecological science (Van Horne and Wiens 1991). Scientific interest in how environmental factors influence species abundance and distribution predates modern ecology (Von Humboldt and Bonpland 1807), but technological advances in computing and remote sensing during the last two decades have allowed ecologists to 
model very complex habitat relationships. In the later part of the $20^{\text {th }}$ century, beginning with interest in managing terrestrial game species and fish populations (Leopold 1933), the development and use of habitat models in ecology became commonplace. Geographical modeling can provide insights and can be used to test both theoretical and applied hypotheses (MacArthur and May 1972). As a research tool, modeling can provide information in a form useful for land managers (Burnham and Anderson 2002; Morrison et al. 1998). For example, modeling exercises can produce maps that classify large tracts in terms of habitat quality. Modeling can also be used to measure and predict future environmental change (Houghton et al. 1990), and their likely effects on plant and animal populations (Lischke et al. 1998). Population modeling has been used to fill gaps in empirical data (Burnham and Anderson 2002), improve vegetation classifications, and to identify focal conservation areas (Margules and Auston 1994).

Although population models can be very informative, all ecological models are approximations of the actual relationships they model. As statistician George Box (1987) said: "Essentially, all models are wrong, but some are useful." Models should be regarded as simplified hypotheses rather than as reality. For birds with a wide geographic distribution like the Golden-winged Warbler, population models can be more appropriate when used at the landscape scale because models used at this scale will be less affected by variation in habitat preference among individuals. These types of habitat models typically lack the 
fine-grain detail to draw conclusions at the site level. Nonetheless, with further validation of these types of models and a better understanding of the techniques used in model development, habitat use models may eventually become more detailed at a smaller spatial scale and provide insights into habitat preferences at the stand/field scale.

\section{Objectives}

The goal of this study was to evaluate the performance of the HSI and HSC population models (Thogmartin and Knutson 2007). Both models were built using remotely sensed habitat data and historic detections of singing Goldenwinged Warblers to predict breeding density. I used empirical field data on breeding abundance in the area modeled by Thogmartin and Knutson (2007) to test the predictive accuracy of the two models and provide suggestions for model improvement. These types of validation exercises allow modelers to refine their methods, eventually advancing the model design process and subsequently providing land managers and conservationists with the most accurate populationhabitat use models available. Ultimately, this could allow land managers and conservation biologists to more efficiently direct limited resources towards focal areas within a smaller time frame, and at a larger spatial scale resulting in more efficient use of resources for the conservation of Golden-winged Warblers in the northern Great Lakes region. 
Here, I evaluate the effectiveness of two population models (HSI and HSC) using empirical data collected for BCR 12. In addition, I use existing presence/absence information, original data on bird locations and vegetation characteristics to evaluate specific environmental characteristics responsible for Golden-winged Warbler presence within the region.

\section{Habitat Modeling}

The most effective habitat use models begin with the most "realistic" model describing correlations between response and predictor variables (Hosmer et al. 2000). For species that rely largely on early successional habitats, it is particularly important to understand how changing habitat associations influence focal species presence or absence (Van Horne and Wiens 1991).

According to Morrison et al. 1998; the goals for many wildlife habitat use models are to:

1. describe understanding about a species or system;

2. identify measurable environmental factors that influence species distribution and abundance;

3. predict future distribution and abundance of a species;

4. identify gaps in our understanding of the relationship between species occurrence and habitat characteristics; and

5. generate and test hypotheses about the species or system of interest. 


\section{A comparison of two population models}

Golden-winged Warbler population abundance was modeled for the Minnesota and Wisconsin portions of BCR 12 (Figs. 4 and 5) (Thogmartin and Knutson 2007). This region, also known as the boreal hardwood transition region, has historically been dominated by coniferous and northern hardwood forests, nutrient poor soils and numerous lakes, bogs and river flowages (Conservancy 2007).

\section{$\underline{\text { Habitat Suitability Index }}$}

The Habitat Suitability Index (HSI) method generates an index of the capacity of a habitat to support a given species based on environmental variables that are typically associated with habitats used by the species. These models are usually developed for individual species and variables are chosen based on published studies and the expertise of individuals who are familiar with the species' life history (Figure 4). The relationships of the variables to one another in a HSI model are expert-derived and because these models are not statistical, they do not emperically relate observances of species to environmental characteristics. However, this does not make this model type less desirable than others given the value of expert opinion and published literature. Species with a few key habitat needs that are well understood can have relatively simple HSI models. 
For example, the Pileated Woodpecker (Dryocopus pileatus) requires only a few resources such as large trees, diseased trees, dense forest stands, and high snag densities (Bull 1975). Within the species' breeding distribution, these key resources are the strongest predictors of Pileated Woodpecker presence (Schroeder 1982). Modeling for species such as this may be simpler than for some others. One limitation faced by modelers when developing any habitat based model is that information on important habitat variables is often scarce. However, recent interest in Golden-winged Warbler population declines has led to much additional research and an improved understanding of breeding habitat use in parts of its range (Confer 1992).

\section{Hierarchical Spatial Count}

The second abundance model created by Thogmartin employed a method known as the Hierarchical Bayesian Spatial Count (HSC) model (Thogmartin et al. 2004b; Thogmartin and Knutson 2006; Thogmartin and Knutson 2007). This method statistically relates numbers of Golden-winged Warblers to variable habitat over large spatial scales while accommodating several characteristics of sampling techniques. The HSC model (Fig 5) employs a Bayesian hierarchical method of modeling. This approach is practical when dealing with complex situations involving many potential problematic effects such as variation in observer skill and survey quality (Link 2002). The model is hierarchical in that it is composed of random variables associated with the model parameters (i.e., 
intercept and slopes of the covariates); these random variables are in turn described by variances that are themselves treated as random variables.

The Golden-winged Warbler data used to construct the HSC model included 1,840 bird counts previously collected along BBS routes between 1981 and 2001 (Thogmartin and Knutson 2004b). Each BBS route consists of $39.2 \mathrm{~km}$ with 50 roadside stops at $0.80 \mathrm{~km}(0.5 \mathrm{mi})$ intervals where all birds detected within a 3-min period are tallied at each stop (USGS 2001). A route-level sum of the counts from each stop is then used as an index of abundance for the development of both HSI and HSC population models. For the BBS data, abundance is defined as the average number of birds counted per route. See Table 1 for a summary of other variables considered.

\section{Methods}

\section{Study Site Selection and Sampling Routes}

By overlapping the $\mathrm{HSI}$ and HSC models using a geographic information system (GIS) (Fig 8), I identified nine categories that would allow me to compare the predictive power of the two models (Table 2). Each category was sampled using roadside surveys for bird detections and compared to one another. These data allowed me to determine how well each model predicted Golden-winged Warbler abundance compared to actual field data on abundance.

I used the Golden-winged Warbler Atlas Project protocol (GOWAP) (Cornell; Barker Swarthout et al. 2009) and the North American Breeding Bird 
Survey (BBS) as guidelines for designing the survey. Sampling routes of 16.1 $\mathrm{km}$ (10 mi) were placed as randomly as possible along drivable roads within sampling "categories" where the two models were within $\pm 15 \%$ agreement of Golden-winged Warbler abundance, and areas where the two models disagreed by $>15 \%$ regarding Golden-winged Warbler abundance (Thogmartin and Knutson 2007). My routes were shorter than those of the BBS mostly due to lack of required road length within some sampling categories. However, like the BBS data, all surveys were conducted along secondary or tertiary roads (Fig 6). (Within Minnesota and Wisconsin, we identified 700 potential point count locations along roadside routes in 2008). All routes were selected based upon sufficient length for the route while maintaining adequate distance $(3.2 \mathrm{~km})$ between routes, to minimize the chance of double counting birds. Route locations were not constrained by other elements such as habitat type because there was limited sample area. I placed 10 routes each: 1 ) within the categories where the models were in agreement, and 2) within the categories where each model disagreed by at least $15 \%$ in predicted Golden-winged Warbler abundance.

Routes that were placed in areas where the HSC predicted higher Goldenwinged Warbler abundance were classified as "higher predicted presence for the HSC model." These routes were also classified as "lower predicted abundance or absence for the HSI model." Thus where one model predicts higher Goldenwinged Warbler abundance, in this same location I assumed the other model predicted a low abundance (or absence) of the bird. For the vegetation analysis, 
points were classified as having "observed presence" if I detected one or more Golden-winged Warbler at the sampling site.

\section{Golden-winged Warbler Surveys}

During the breeding season, the Golden-winged Warbler has two distinct territorial vocalizations, the Type I and Type II songs. Male Golden-winged Warblers generally use their Type I song (Type A or primary song) phonetically described as "zee buzz buzz buzz" to attract mates and define territory areas. The Type II song (Type B secondary song) is often associated with aggression between other Golden-winged Warbler males and begins with an almost rapid "stutter followed by a lower buzzy note."

I used state gazetteers and a global positioning system (GPS) unit to find the starting point of each route, and navigated to each point along the routes (at $0.5 \mathrm{mi}$ increments as in the BBS) using an automobile odometer. At each sample point, I used a portable compact disc player with a recording of the Golden-winged Warbler Type I and Type // songs. Each count began with a passive 3-min listening period, followed by a 5-min Type / song playback, 1-min passive listen, 1-min Type // playback, and finished with 1-min passive listening period. When a Golden-winged Warbler was detected, the observer (AW or JG) recorded the period in which the Golden-winged Warbler was first observed (as 
well as the specific minute), and whether the Golden-winged Warbler was female or male if it was seen.

In northern Wisconsin, Golden-winged Warblers typically arrive in midMay (A. Roth personal communication) and will display a strong response to recorded song playback for six weeks after arrival (Kubel and Yahner 2007). Population sampling was conducted between 25 May - 1 July 2008. Sampling began 30 min prior to sunrise each morning and was completed by 11 am each day to take advantage of the known period of peak singing by Golden-winged Warbler (Rosenberg 2005) (Figure 7). Sampling was not conducted on days with rain or high wind because this is known to reduce auditory detections (Emlen and DeJong 1981).

\section{Vegetation Data}

Vegetation data collected using the GOWAP protocol included general habitat type, amount of water present, and three dominant plant species in each of the tree, shrub and herb strata. The dominant species were identified from the roadside count location as the three most common species within each stratum. Successional stage was estimated for each survey point based on the size and age of the trees within $50 \mathrm{~m}$ of the survey point. Early successional habitat included seedlings and small saplings; trees $<6.1 \mathrm{~m}$ tall, about 0-6 years old, or $<30 \mathrm{~cm} \mathrm{DBH}$ on average. Mid-successional habitat included large saplings and pole timber; trees 6.1-12.2 m tall, about 6-20 years old, or 3-12 cm DBH on 
average. Late succession included large pole and saw timber; trees $>12.2 \mathrm{~m}$ tall, $>20$ years old, or $>12 \mathrm{~cm} \mathrm{DBH}$ on average. Densities of the three vegetation layers were classified as either sparse, medium, or dense depending on whether each type of strata covered $<20 \%, 20-60 \%$ or $>60 \%$ respectively within a $50 \mathrm{~m}$ radius of the sample point. These vegetation data were classified to identify individual site characteristics that are good predictors of Golden-winged Warbler presence.

\section{Model Performance}

Geographic regions where the models were in agreement and predict similar Golden-winged Warbler abundances were modeled by overlapping the two predictive models using GIS. Because there was a limited amount of abundance information available from the BBS, contingency tables were used for comparing actual empirically estimated population values with those predicted by the models (Dallal 2008) (Table 3). I completed 3x3 contingency tables to 1) compare the HSI with the empirical data 2) compare the HSC with the empirical data and 3) to compare the HSI model prediction against the HSC model prediction. This allowed me to determine (given the two model predictions) how well each model classified Golden-winged Warbler abundance based on my 2008 surveys. The number of Golden-winged Warblers recorded was entered into each $3 \times 3$ contingency table (Tables $4,5 \& 6$ ) depending on the category in which the bird was recorded. I performed a Chi-square test with $\mathrm{df}=4$ and alpha 
$=0.10<P<0.05$ to verify whether or not my observations agree with the theoretical distribution determined by the models. My null hypothesis was that Golden-winged Warbler abundance based on my surveys was independent of the model predictions; the alternative hypothesis was that my observed Goldenwinged Warbler abundance levels were dependant on the predicted abundance of the two models. Once I reject or accept the null hypothesis I would like to calculate discrepancy between the models using the contingency table and calculating the error of commission between models. The error of commission represents the percentage of sampled areas where the model predicted presence yet the Golden-winged Warbler was absent.

\section{Generalized Linear Models}

My second objective was to determine which vegetation variables were important factors predicting the presence of Golden-winged Warblers on the site level. Using the statistical program $R$, I tested the null hypothesis that the probability of finding a Golden-winged Warbler at a given location is independent of the vegetative descriptors we collected. Generalized linear mixed effects models are described by the 'glmer' command (this is similar to the 'Im' (linear model)) function except that for generalized linear models, one must specify the type of linear model that is desired. In this instance, I used a logistic regression analysis (link=logit) in which presence or absence is the dichotomous dependent variable. I used mixed-effects because the data are clustered into routes. 
Because I used presence/absence bird data, I first converted my nominal data (i.e. vegetation type, successional stage etc.) into factor variables that could be compared accurately to the presence/absence data. For parabolic data such as time of day (Time) or day of year (DOY), I used both Time and Time ^ 2 and DOY and DOY^2 into the formula because there is a "peak" in the data.

I began the modeling process by first including all vegetative variables that have previously been shown to influence Golden-winged Warbler habitat use and have been noted as important in Golden-winged Warbler habitat preference in the models (Barker Swarthout et al. 2009). I developed nine models in 'R', fit by the Laplace approximation (Wolfinger 1993) to relate the vegetation variables with Golden-winged Warbler presence/absence as shown below:

$$
\text { Presence } \sim \text { Variable1 + Variable2 ....+(Pnt/Rte), }
$$

This is to be read as "Golden-winged Warbler Presence is a function of Variable1 $+\ldots$... where point and route are the random effects. The variables that comprised each $\mathrm{R}$ model were those that I found to be significant in describing Golden-winged Warbler presences.

The specific variable names used in the analysis are listed below with codes in parentheses follow:

1) Surface water (Surface.water) - dry, moist or wet

- Dry: dry or upland habitat, Moist: some standing water, $<10 \%$ of area within 50 meters of survey point, Wet: very wet area, between $>10 \%$ standing water within $50 \mathrm{~m}$ of survey point 
2) Shrub density (DensShrub) - sparse, medium or dense

- Relative density of woody shrubs (1-4m tall) within $50 \mathrm{~m}$ radius of survey point. Sparse: less than $20 \%$ woody shrub cover, Medium: between $20 \%-60 \%$ woody shrub cover, Dense: over $60 \%$ woody shrub cover

3) Tree density (DensTree) - sparse, medium or dense -Relative density of trees $>4.5 \mathrm{~m}$ tall within $50 \mathrm{~m}$ radius of survey point. Sparse: less than $20 \%$ cover of trees, medium: between $20 \%-60 \%$ cover of trees, dense: over $60 \%$ cover of trees

4) Herb density (DensHerb) - sparse, medium or dense -Relative density of grassy and herbaceous patched within $50 \mathrm{~m}$ radius of survey point. Sparse: less than $20 \%$ grass/herb cover, medium: between $20 \%-60 \%$ grass/herb cover, dense: over $60 \%$ grass/herb cover

5) Successional stage (Succession) - early, mid, late -Early: seedlings and small saplings, trees $<6 \mathrm{~m}$ tall, about 0-6 years old or $<3 \mathrm{~cm}$ DBH on average; middle: large sapling and pole timber, trees $6-12 \mathrm{~m}$ tall, about 6-20 years old or 3-12cm DBH on average; late: large pole and saw timber, trees $>12 \mathrm{~cm} \mathrm{DBH}$ on average.

6) Dominant Shrub (DomShrub) - the three dominant woody shrubs (1-4 m tall) were recorded within a 50 meter radius of the survey point.

7) Dominant Herb (DomHerb) - the three dominant herbs were recorded within a $50 \mathrm{~m}$ radius of the survey point.

8) Dominant Tree (DomTree) - the three dominant trees $>5 \mathrm{~m}$ tall were 
recorded within a $50 \mathrm{~m}$ radius of the survey point

Akaike's information criterion (AIC) was used to evaluate each model as a measure of goodness of fit. This is similar to the Bayesian Information Criterion $(\mathrm{BIC})$ in that it is not in itself a test of the model but rather a way of comparing models that are given a value and can be ranked. Several models were developed and ranked according to $\mathrm{AIC}$, with the lowest $\mathrm{AIC}$ value representing the most parsimonious and best fit model.

\section{$\underline{\text { Results }}$}

\section{Survey Results}

Among 700 roadside point counts, I detected 187 Golden-winged Warblers. Figure 9 shows the proportion of Golden-winged Warblers observed per model. These percentages represent individual Golden-winged Warblers recorded: 1) where the HSI had a greater prediction, 2) areas where the HSC had a greater prediction and 3) areas where the models agree on Golden-winged Warbler abundance (Figure 9). Figure 9a shows the percentage of Goldenwinged Warblers recorded during each time segment of the sampling sequence.

The number of Golden-winged Warblers recorded within the sample categories where each model (HSI or HSC) demonstrated different predictions was distributed fairly evenly. The time segment in which the birds were recorded (Figure 9) show that nearly $80 \%$ of the Golden-winged Warblers were recorded 
during the first two time segments. These segments included a 3-min passive listen followed by the Type I song playback.

\section{Model Performance}

Overall, 35 routes containing 20 stops (for a total of 700 sample points) were used in the analyses. Figure 10 shows Golden-winged Warbler presences by state and model. Ideally, the mean observed count should increase as the number of birds predicted by the models increase. The mean observed counts are spread fairly evenly across the predictions. However, the mean observances for the HSC model in Wisconsin seem to be performing well. The percentage of Golden-winged Warbler absences are also spread fairly evenly across each model prediction. The HSC model shows decreased absences as model prediction increases for Wisconsin, which should be expected.

Data were distributed within states and again between models and model predictions (Table 7). The calculated error of commission for each model is shown in Table 8. These values represent the percentage of sites where the model predicted Golden-winged Warblers yet they did not occur.

The contingency table analysis compares each model against the empirical data and then one model against the other. Each cell represents the total recorded Golden-winged Warblers within each sample category (Table 5). For the comparison, I performed a $\mathrm{X}^{2}$ statistical test on the values shown in Table 5. The resulting "expected" contingency table is shown in Table 6, with $\mathrm{df}=4$ and 
alpha $=0.10<P<0.05$ the $X^{2}$ value $=32.2$. This allowed me to reject the null hypothesis that Golden-winged Warbler abundance is independent of the models' predictions. In the contingency table, there were 29 sites where the HSI model predicts Golden-winged Warbler absence and only two areas where both models agree on absence (Table 5). To calculate the error of commission, I divided the two areas by the 29 total areas and find the HSI model has a $6.9 \%$ chance of correctly classifying absences in the HSC model.

Similarly, there were 60 sites where the HSC model predicted Goldenwinged Warbler absence and the HSI model predicted presence (top row of Table 5); two of these 60 areas are where the models agreed on absence. By dividing the 2 agreement areas into the 60 sample areas we find that the HSC model has a 3.3\% chance of correctly classifying absences in the HSI model.

\section{Generalized Linear Models}

The model that states "Golden-winged Warbler presence is a function of dominant shrub, shrub density, dominant herb and level of succession" is the best fit based on the Akaike's criterion value (Table 9). Of all sites where Golden-winged Warblers were recorded, $43 \%$ were recorded where tag alder (Alnus rugosa) was the dominant shrub, 22\% where hazelnut (Corylus americana) was the dominant shrub, and $20 \%$ where Aspen (Populus spp.) was the dominant shrub. At the herbaceous level, grasses were present at $95 \%$ of sites with Golden-winged Warblers. Shrub density proved to be a significant 
variable at Golden-winged Warbler locations, $56 \%$ of occupied sites were "dense" (>60\% woody cover) and 33\% were "medium" (20-60\% woody cover). As expected, the successional stage significantly predicted Golden-winged Warbler presence with $76 \%$ points what birds were detected classified as midsuccessional (trees $6-12 \mathrm{~m}$ tall or $3-12 \mathrm{~cm}$ DBH on average). The ideal site would be mid-successional trees $6-12 \mathrm{~m}$ tall or $3-12 \mathrm{~cm} \mathrm{DBH}$ on average) with dense shrubs (of alder, aspen and/or hazelnut), and grasses and/or sedges for nesting (Confer 1992).

Surface water was not significant in the model formula. Of all sites where Golden-winged Warbler presence was recorded, 79\% ( $n=147)$ were located within dry-moist soils; only $20 \%$ of Golden-winged Warblers were detected in wet areas.

\section{Discussion}

Direct comparisons of habitat-abundance model predictions with field data are essential for evaluating the quality of the models and in refining modeling techniques. Thogmartin predicted Golden-winged Warbler abundance within BCR 12 using previously known habitat associations: BBS counts, and hierarchical models at multiple spatial scales. Thogmartin's models assumed that certain habitat characteristics are significant descriptors of Golden-winged Warbler abundance. The objectives of this study were to evaluate the performance of these two models using empirical data, to identify vegetation 
characteristics at the site level that are positively associated with Golden-winged Warbler presence, and to offer suggestions for future model refinement.

I used a combination of sampling techniques for the roadside surveys including methods used in the BBS protocol and the Golden-winged Warbler Atlas Project protocol. A review of the number of birds recorded during different time intervals of the survey period at each point showed that the use of the Type I/ song during the sampling segment was not critical for improving detection of Golden-winged Warbler. Nearly $80 \%$ of all birds counted were observed within the 3-min passive listen followed by a 5-min Type / song playback. This finding was contradictory to Kubel and Yahner 2007 who found that when sampling in a mixed-shrubland forest using both passive point counts and playback, the observer recorded only $30 \%$ of all possible detections. However, they also noted that this was largely due to habitat size and structure. For example, when sampling a utility right-of-way clear-cut, the rate of accurate prediction increased to $80 \%$.

Observed data seems to be distributed fairly evenly across states and model predictions, with the exception of the HSC model in Wisconsin that follows the model predicted trend increasing bird abundance as model predicted abundance increases; predicted absences would decrease as the model prediction increased. These data suggest that within Minnesota, patterns of bird occurrence are not consistent with the both model predictions. In Wisconsin, actual bird occurrence does not follow the HSI model predictions whereas the 
HSC model seems to perform well. The error of commission values for Minnesota show the HSI and the HSC predicted presences where there were absences at $23 \%$ and $24 \%$ of all sample sites respectively. In Wisconsin, the $10 \%$ error of commission for the HSC model suggests that the model is slightly better at accurately predicting true presences.

The contingency table analysis allowed me to compare each model against empirical data and each model against the other. Using values in Table 5 the error of commission values show that the HSI model had a $6.9 \%$ chance of correctly classifying absences in the HSC model, whereas the HSC model had a $3.3 \%$ chance of correctly classifying absences in the HSI model. The Chi-square test was used to verify whether or not the observations agree with the both models' predicted distributions. The results show that observed Golden-winged Warbler abundance is independent of model predictions.

In Wisconsin the HSC model performed better than the HSI model but neither model performed well in Minnesota. Secondly, I wanted to determine whether these models could be complementary to each other; I was able to determine that neither model would improve the performance of the other.

These results suggest that neither model seems to work well enough at the site level to accurately predict Golden-winged Warbler abundances across the upper Midwest. I would suggest only site level data as the most effective way to predict Golden-winged Warbler abundances. For future models I would suggest the use of field collected data, variables only known to be highly correlated with 
Golden-winged Warbler presence, as well as a greater emphasis on successional stage and stem density.

Using our vegetation data, I was able to identify some habitat variables at the site level that can be used to strengthen the Golden-winged Warbler model. The variable variables found to be significant Golden-winged Warbler habitat when used in combination with one another are: dominant shrub species (particularly alder, hazelnut or aspen), dominant herbaceous species (grasses and/or sedges), shrub density, and successional stage (particularly mid-successional. These findings are similar to Roth and Lutz (2004) who noted the greatest densities of singing males in the seedling stage of aspen forest succession. My study highlights the importance of young seedlings or shrubs in Golden-winged Warbler territories.

Based on previous knowledge of Golden-winged Warbler habitat, my findings highlight the importance of a dense grass or herbaceous level used for nesting sites (Klaus and Buehler 2001; Bulluck and Buehler 2008). Golden-winged Warblers are a ground nesting species that create an open cup nest composed of grasses, bark and dead leaves. These nesting sites were non-random and often included a woody stem (Bulluck and Buehler 2008).

Golden-winged Warblers are associated with early successional forests in the seedling stage, or with shrubby areas for nesting territories (Confer and Knapp 1981). Shrubs and small trees are used for nesting cover as well as for foraging. The Golden-winged Warbler generally uses the parts of these small trees and 
shrubs to glean arthropods from both live and dead "curled" leaves (www.birds.cornell.edu/gowap/account.html). This study found $56 \%$ of all Golden-winged Warbler sites included a dense shrub layer; this emphasizes the importance of these dense shrubby areas potential nesting sites.

Golden-winged Warbler territories also often contain prominent emergent trees used as "song perches." Rossell (2001) found that $>75 \%$ of singing males chose song perches in the upper parts of canopy trees. Such trees were often associated with forest edges or were found near the edges of water, perhaps to increase the male's ability to display and communicate across a larger area.

A number of researchers have suggested that good Golden-winged Warbler nesting habitat often contains wet to very wet areas (Confer and Knapp 1979). The findings of this particular study found at each Golden-winged Warbler location, $79 \%$ ( $n=147)$ were located within dry-moist soils; only $20 \%$ of Goldenwinged Warblers were detected in wet areas. Both ideals may be true, habitat preference may be site specific as a number of other findings suggest that Golden-winged Warblers are not habitat specialists but rather generalists (Will 1986; Conservancy 1998).

Ultimately, studies like this will enable land managers and conservation biologists to identify areas with the highest likelihood of supporting viable Goldenwinged Warbler populations. Remotely sensed data can be useful to classify large areas without the time consuming ground-visit to each location. This can be accomplished using vegetation and environmental variables known to be 
important for Golden-winged Warbler habitat. However, the use of remotely sensed data is limited by the autecology of the species of interest. For example, this study has identified the importance of successional stage for Golden-winged Warbler habitat, and others have noted the importance of song perch trees (A. Roth, personal communication). Because these types of variables are dynamic, the needs of species that depend on them can be hard to capture as GIS layers. This is where ground-visits are essential.

In addition, one can identify areas where Golden-winged Warbler may have been in the past (eg. mature aspen [Populus spp.] stands) and modify the areas through rotational, even-aged cuttings or other techniques in order to promote Golden-winged Warbler re-use of the area (Roth and Lutz 2004).

This is just one type of model validation project that allows modelers to refine their methods, eventually advancing the model design process and subsequently providing land managers and conservationists with the most accurate population habitat use models.

\section{Future Research}

For future research, vegetation composition should be evaluated in more detail. For example, at each sample location, I did not record the proximity to forest edge or the characteristics of song perches and this is a variable that could be examined in the future. These types of complex vegetation relationships, 
coupled with previously recorded data, and remote sensing technology could ultimately yield a more accurate and useable model.

Recent advances in remote sensing technology called light detection and ranging (LiDAR) allows for the measurement of various properties such as distance to an object or surface using laser pulses. Once available at the regional scale, modelers can use this technology to classify habitat structure with far more accuracy than in the past (Asner et al. 2008, Reutebuch et al. 2005, Bowen and Waltermire 2002). This is useful across many disciplines, and has been shown to provide unique information regarding habitat structure when modeling for bird usage (Goetze et al. 2007). 


\section{References:}

Asner, G. P., D. E. Knapp, T. Kennedy-Bowdoin, M. O. Jones, R. E. Martin, J. Boardman, and R. F. Hughes. 2008. Invasive species detection in Hawaiian rainforests using airborne imaging spectroscopy and LiDAR. Remote Sensing of Environment 112:1942-1955.

Barker Swarthout, S., K.V. Rosenberg, R.W. Rohrbaugh, Jr, and R.S. Hames. 2009. Golden-winged Warbler Atlas Project. Final Report to United States Fish and Wildlife Service: 1999-2006 Breeding Seasons in U. S. Fish \& Wildlife Service.

Bowen, Z. H., and R. G. Waltermire. 2002. Evaluation of light detection and ranging (LIDAR) for measuring river corridor topography $\langle$ sup $>1</$ sup $\rangle$. Journal of the American Water Resources Association 38:33-41.

Box, G., and N. Draper 1987. Empirical model-building and response surfaces.

Buehler, D. A., J. L. Confer, R. A. Canterbury, T. C. Will, W. C. Hunter, R. Dettmers, and D. Demarest. 2006. Status Assessment and Conservation Plan for the Golden-winged Warbler, Vermivora chrysoptera, in the United States. Fish \& Wildlife Service. U. S. Department of the Interior, Biological Technical Publication FWS/BTP-R6XXX-2006, Washington D.C.

Bull, E. L. 1975. Habitat utilization of the pileated woodpecker, Blue Mountains, Oregon. Oregon State University. Dissertation

Bulluck, L., and D. Beuhler. 2008. Factors influencing Golden-winged Warbler (Vermivora Chrysoptera) nest-site selection and nest survival in the Cumberland Mountains of Tennessee. The Auk 125:551-559.

Burnham, K. P., and D.R. Anderson, 2002. Model selection and multimodel inferece: A practical information-theoretic approach.

Confer, J. L., and Knapp, K. 1979. Golden-winged Warbler and Blue-winged Warblers: The relative success of a habitat specialist and a generalist. The Auk 98:108-114.

Confer, J. L. 1992. Golden-winged Warbler (Vermivora chrysoptera), The Birds of North America Online (A. Poole, Ed.). Page Retrieved from the Birds of North America Online: http://bna.birds.cornell.edu/bna/species/020doi:010.2173/bna.2120. Cornell Lab of Ornithology Ithaca. 
Confer, J. L. 1992. Species Management Abstract: Golden-winged Warbler (Vermivora chrysoptera) in The Nature Conservancy, Arlington, Virginia Conservancy, American Bird. 2007. BCR 12 Boreal Hardwood Transition.

Conservancy, The Nature 1998. Species Management Abstract: Golden-winged Warbler (Vermivora chrysoptera) in T. N. Conservancy, Arlington, Virginia.

Dallal, G. E. 2008. Contingency Tables. http://www.jerrydallal.com/LHSP/ctab.htm

Emlen, J. T., and M. J. DeJong. 1981. The application of song detection threshold distance to census operations. Studies in Avian Biology 6:346352.

Frech, M. H., and J.L. Confer. 1987. The Golden-winged Warbler: Competition with the blue-winged warbler and habitat selection in portions of southern, central and northern New York. Kingbird 37:65-71.

Gill, F. B. 1997. Local cytonuclear extinction of the Golden-winged Warbler. Evolution 51:519-525.

Goetze, S., D. Steinberg, R. Dubayah, and B. Blair 2007. Laser remote sensing of bird species richness and habitat use in the Northeastern United States. Remote Sensing of Environment 108:254-263.

Hands, H. M., R. D. Drobney, and M. R. Ryan. 1989. Status of the golden-winged warbler in the northcentral United States. U.S. Fish \& Wildlife Service, Twin Cities, Minn.

Heilman, G. E., Jr., J.R. Strittholt, N.C. Slosser, and D.A. DellaSala. 2002. Forest fragmentation of the conterminous United States: Assessing forest intactness through road density and spatial characteristics. BioScience: 411-422.

Hosmer, D. W., and S. Lemeshow. 2000. Applied Logistic Regression. John Wiley \& Sons, Inc., New York.

Houghton, J., G.J. Jenkins, and J.J. Ephraums 1990. Climate change - The IPCC scientific assessment. Cambridge University Press, Cambridge, England and New York.

Klaus, N., and D. Beuhler. 2001. Golden-winged Warbler breeding habitat characteristics and nest success in clearcuts in the southern Appalachian mountains. The Wilson Bulletin 113:297-301.

Kubel, J. E., and R.H Yahner. 2007. Detections probability of GWWA during point counts with and without playback recordings. Journal of Ornithology 78:195-205.

LeBrun, J. J., W.E. Thogmartin, and J.R. Miller. 2009. Evaluating the ability of regional models to predict local avian abundance. Fisheries \& Wildlife Sciences. Univeristy of Missouri Columbia, Columbia, Missouri

Leopold, A. 1933. Game management. Scribner, New York.

Link, W. A., E. Cam, J.D. Nichols, and E. Cooch. 2002. Of Bugs and Birds: Markov Chain Monte Carlo for Hierarchical Modeling in Wildlife Research. Journal of Wildlife Management 2: 277-291. 
Lischke, H., A. Guisan, A. Fischlinand, and H. Bugmann. 1998. Vegetation responses to climate change in the Alps-Modeling studies. In: A View from the Alps: Regional Perspectives on Climate Change. Pages 309-350.

MacArthur, R. H., and R.M. May. 1972. Niche Overlap as a Function of Environmental Variability. Proceedings of the National Academy of Sciences 69:1109-1113.

Margules, C. R., and M.P. Austin. 1994. Biological models for monitoring species decline: the construction and use of data bases. Philos. Trans. R. Soc. Lond. B 344:69-75.

Morrison, M. L., B. G. Marcot, and R. W Mannan. 1998. Wildlife-habitat relationships: concepts and applications. University of Wisconsin, Madison, WI.

PIF. 2007. Partners in flight landbird population estimates database in R. M. B. Observatory.

Reutebuch, S. E., H.E. Andersen, and R. J. McGaughey. 2005. Light detection and ranging (LIDAR): An emerging tool for multiple resource inventory. Journal of Forestry 103:286-292.

Rich, T. D., C.J. Beardmore, H.Berlanga, P.J. Blancher, M.S. Bradstreet, G.S. Butcher, D. Demarest, E.H. Dunn, W.C. Hunter, D. Inigo-Elias, J.A. Kennedy, A. Martell, A. Panjabi, D. N Pashley, K.V. Rosenberg, C. Rustay, S. Wendt, and T. Will. 2004. Partners in flight north american landbird conservation plan. Cornell Lab of Ornithology Ithaca, New York, USA.

Rosenberg, K. V., and P.J. Blancher. 2005. Setting numerical population objectives for priority landbird species. USDA Forest Service.

Roth, A. M., and S. Lutz. 2004. Relationship Between Territorial Male GoldenWinged Warblers in Managed Aspen Stands in Northern Wisconsin, USA. Forest Science 50:153-161.

Sauer, J. R., J. E. Hines, and J. Fallon. 2008. The North American Breeding Bird Survey, Results and Analysis 1966 - 2007. USGS Patuxent Wildlife Research Center, Laurel, MD.

Schroeder, R. L. 1982. Habitat suitability index models: Pileated Woodpecker

Stucker, S. 2009. Golden-winged Warbler - Minnesota Profile. Minnesota Conservation Volunteer

Team, R Development. 2008. R: A language and environment for statistical computing. R Foundation for Statistical Computing, Vienna, Austria.

Thogmartin, W. E., J. R. Sauer, and M. G. Knutson. . 2004. A hierarchical spatial model of avian abundance with application to Cerulean Warblers. . Ecological Applications:1766-1779.

Thogmartin, W. E., M.G. Knutson, and J.R. Sauer. 2006. Predicting regional abundance of rare grassland birds with a hierarchical spatial count model. The Condor 108:25-46. 
Thogmartin, W. E., and M. G. Knutson. 2007. Mapping Golden-winged Warbler abundance to improve regional conservation. U.S. Geological Survey, Upper Midwest Environmental Sciences Center La Crosse, WI.

Van Horne, B., and J.A. Wiens. 1991. Forest Bird Habitat Suitability Models and the Development of General Habitat Models. U.S. Fish \& Wildlife Service, Washington D.C.

Von Humboldt, A., and A. Bonpland. 1807. Essai sur la géographie des plantes, Paris.

Will, T. 1986. The behavioral ecology of species replacement: Blue-winged and Golden-winged Warblers in Michigan. University of Michigan, Ann Arbor. Dissertation

Will, T. 2009. Golden-winged Warbler Working Group Petition to List the Goldenwinged Warbler under the Endangered Species Act.

Wolfinger, R. 1993. Laplace's approximation for nonlinear mixed models. Biometrika 80:791-795. 


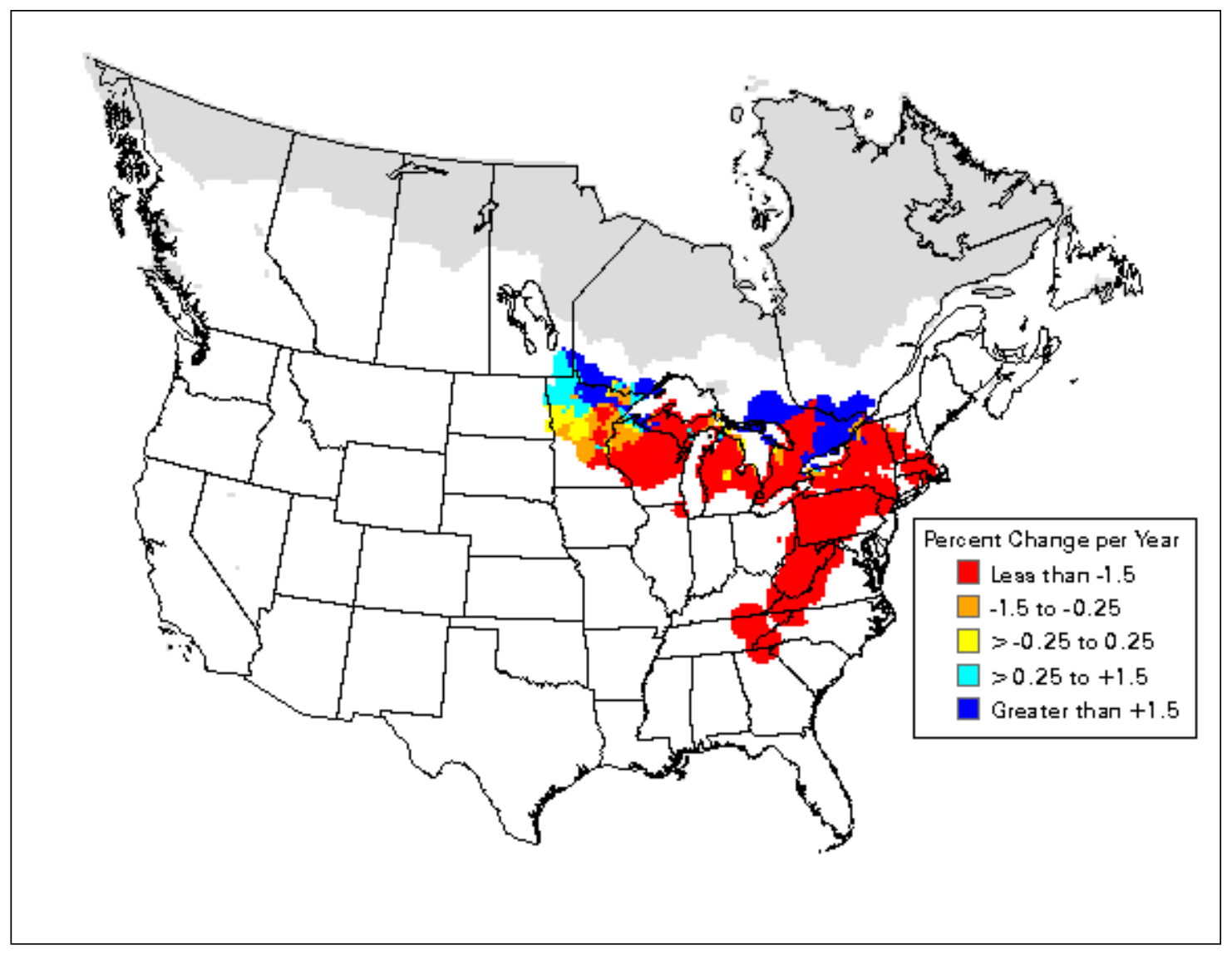

Figure 1. Golden-winged Warbler (Vermivora chrysoptera) Breeding Bird Survey Trend Map, 1966-2003 (Sauer et al. 2008). 


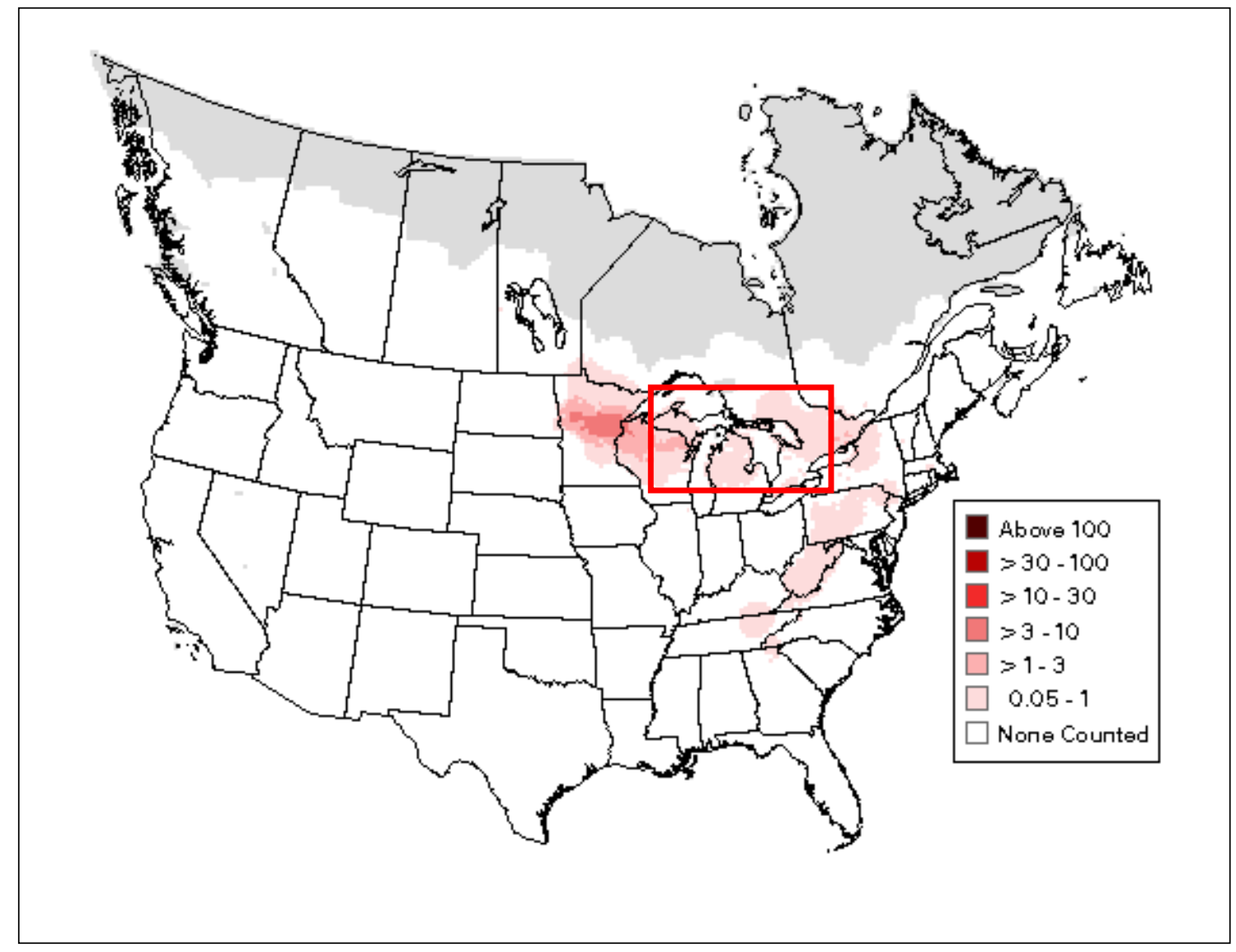

Figure 2. Golden-winged Warbler BBS summer distribution map 1994-2003 (Sauer 2008) Study area in the Boreal Hardwood Transition region outlined in red. 


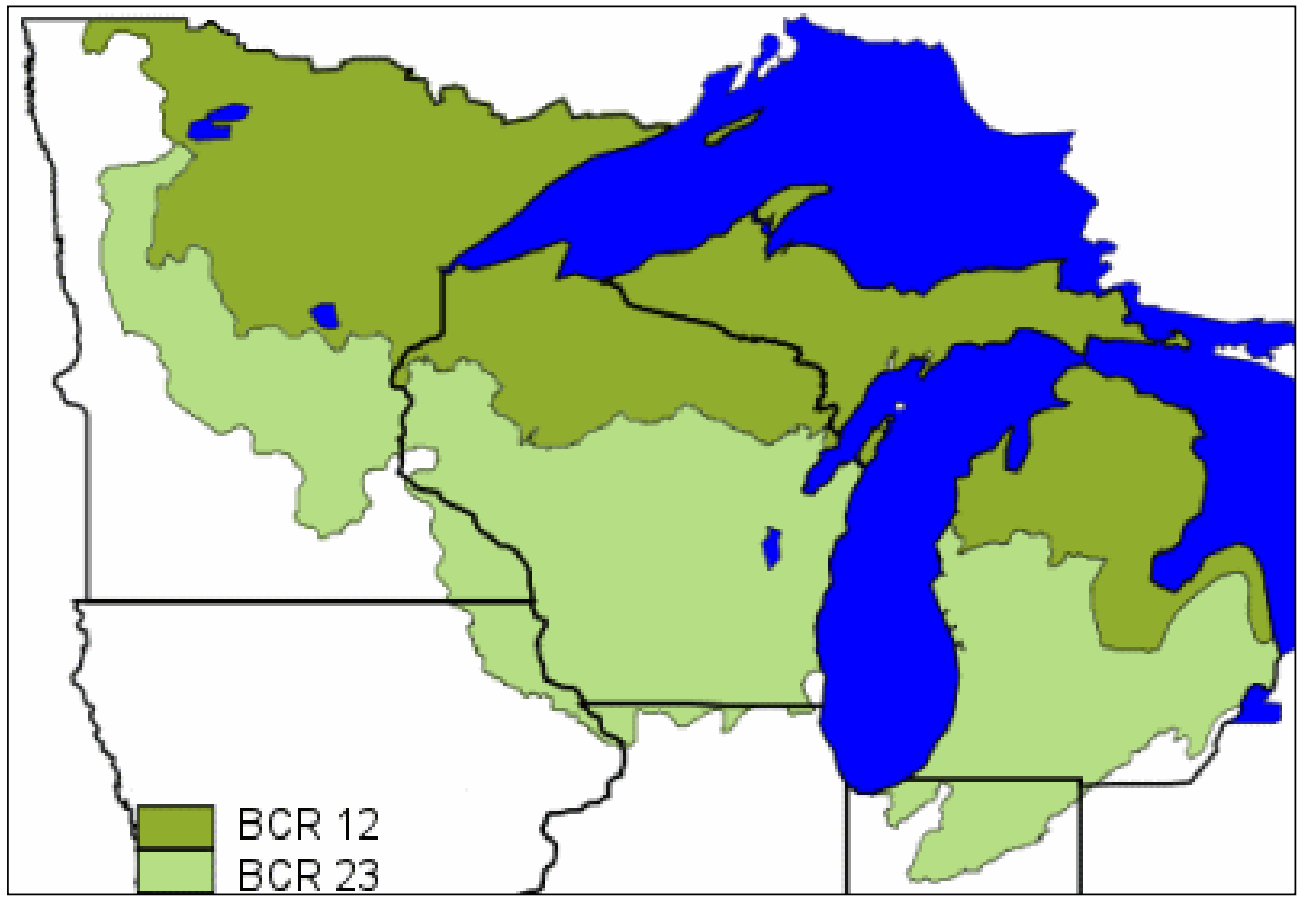

Figure 3. Bird Conservation Regions 12 and 23. 


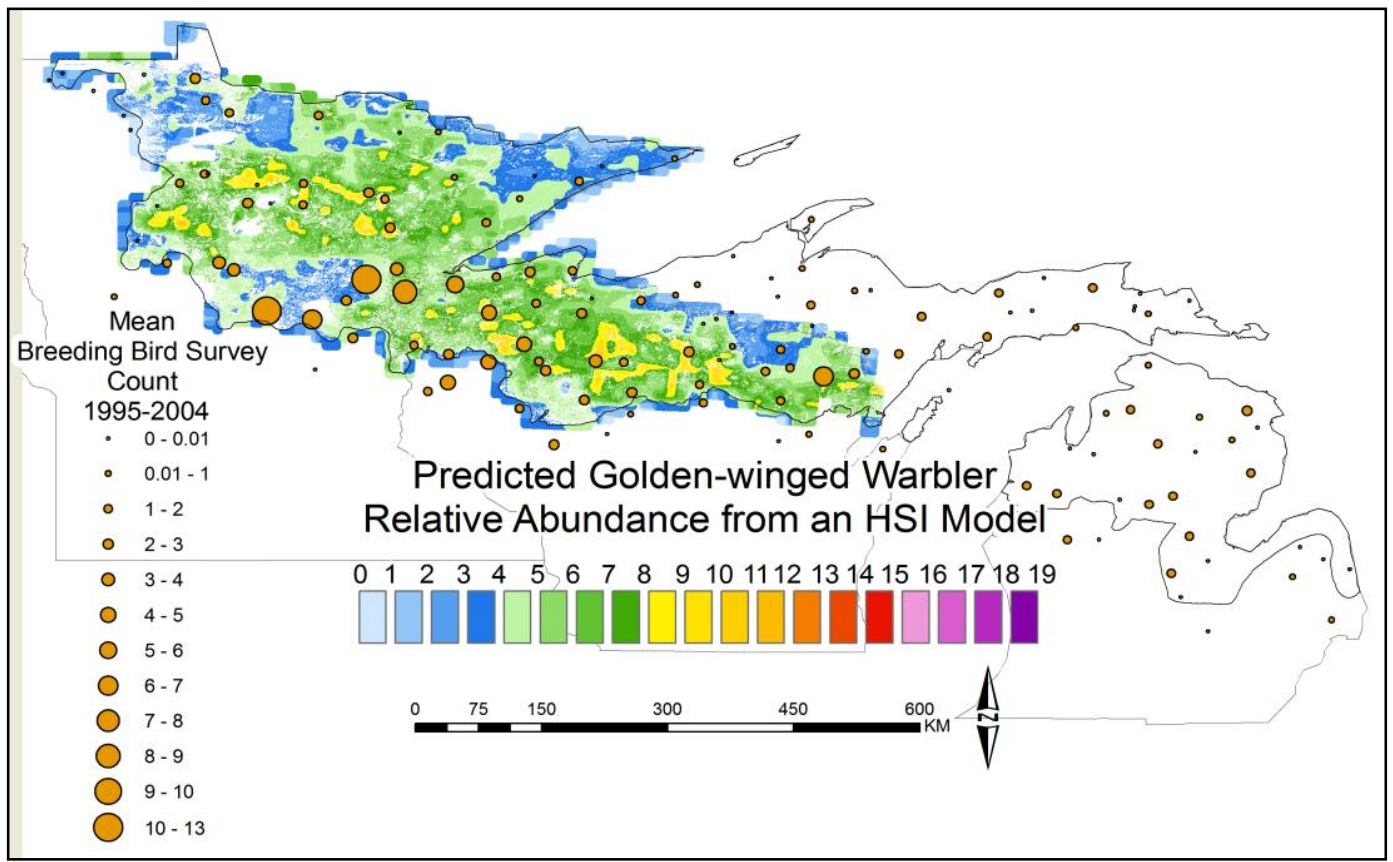

Figure 4. Habitat Suitability Index model for GWWA in BCR 12 (Thogmartin)

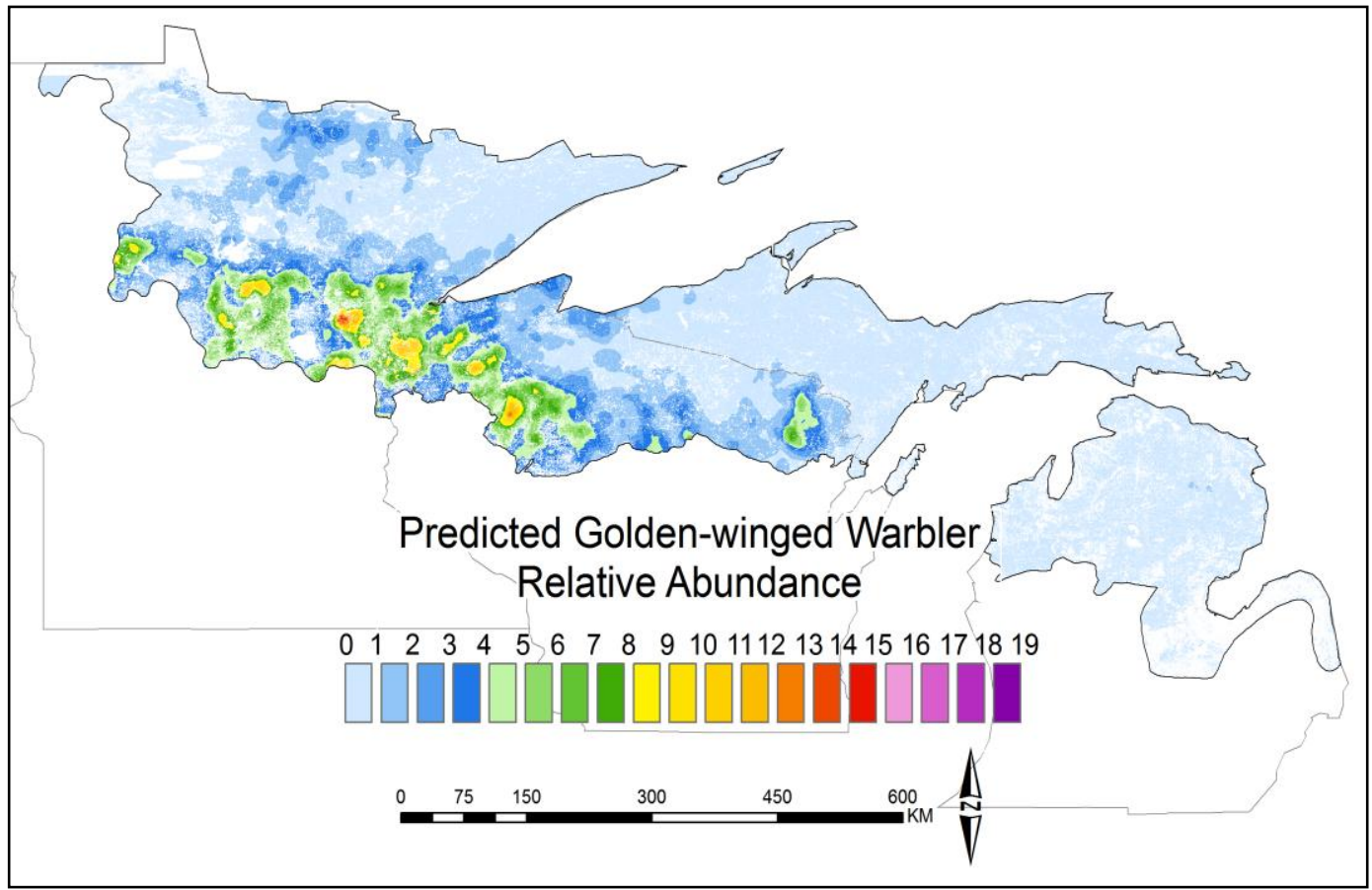

Figure 5. Hierarchical Spatial Count model for the Golden-winged Warbler in BCR 12 (Thogmartin). 


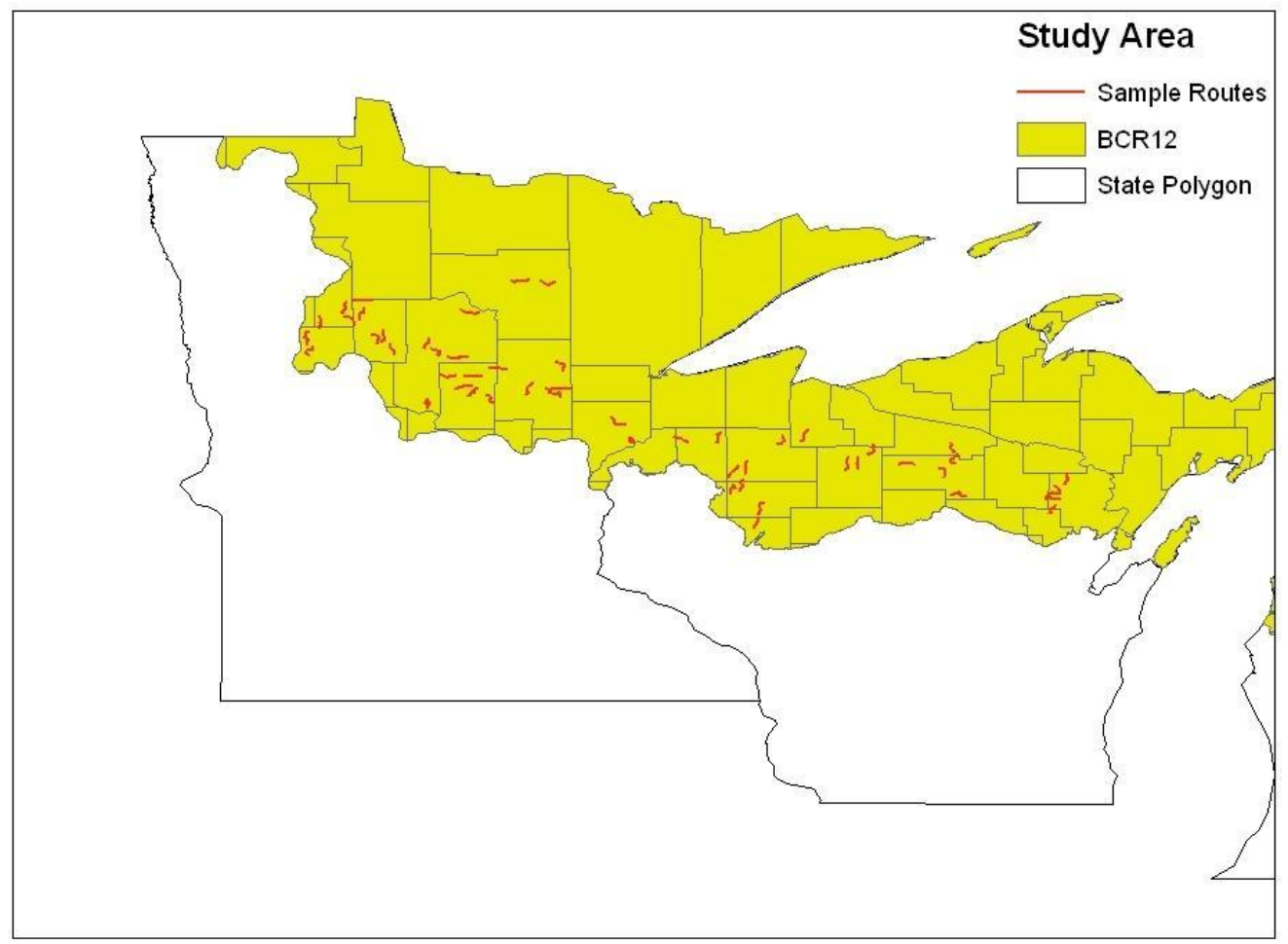

Figure 6. Map showing study area in the Upper Midwest including sampling routes. 


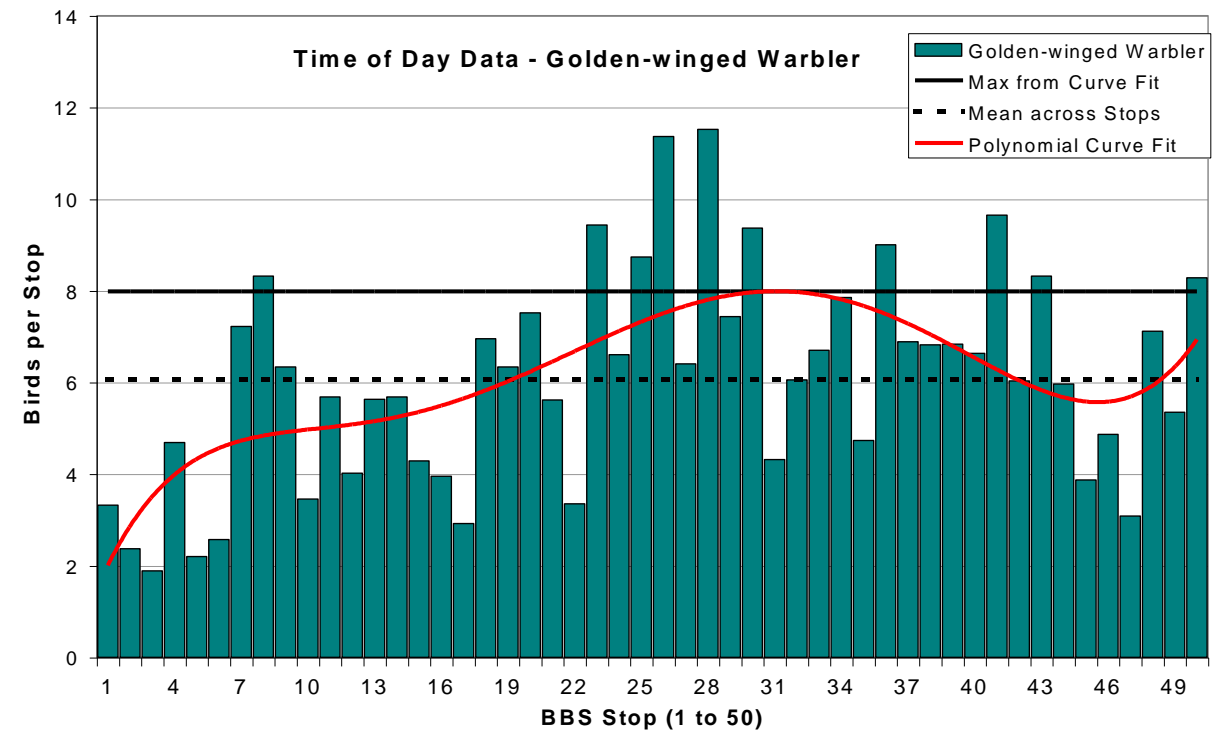

Figure 7. Time of day detectability curve from Rosenberg 2005. 


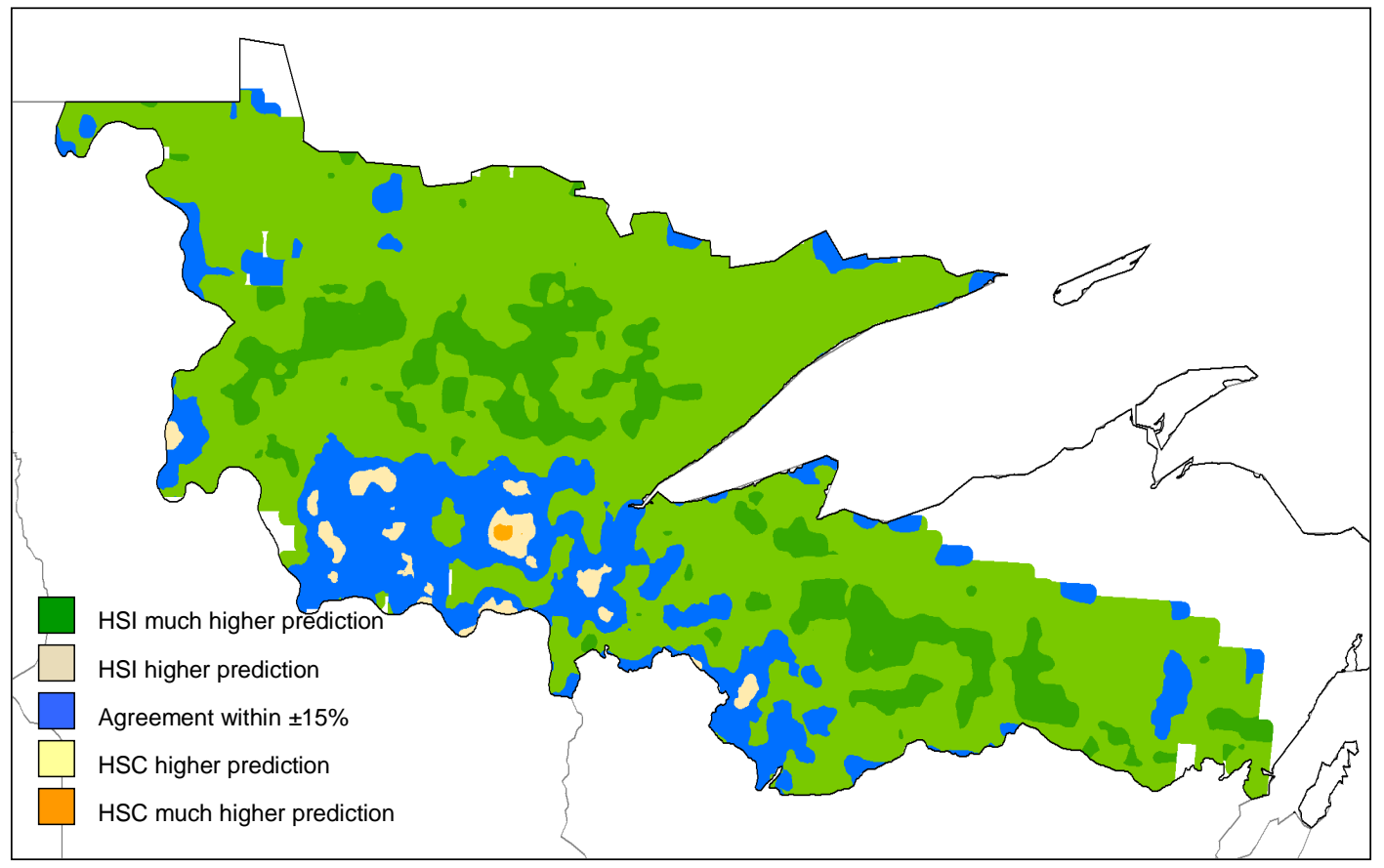

Figure 8. Map showing the overlap of the HSI and HSC models (Thogmartin). 


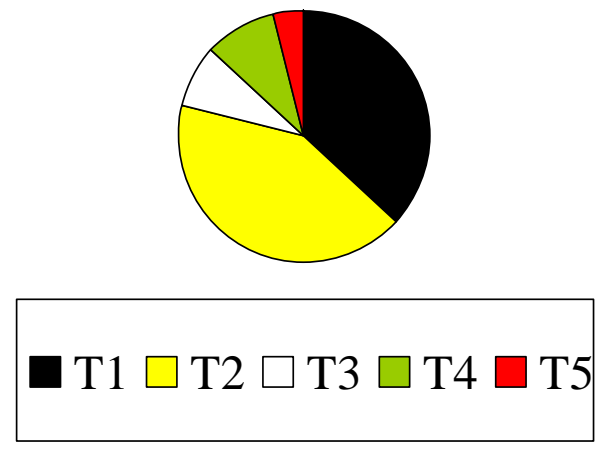

a

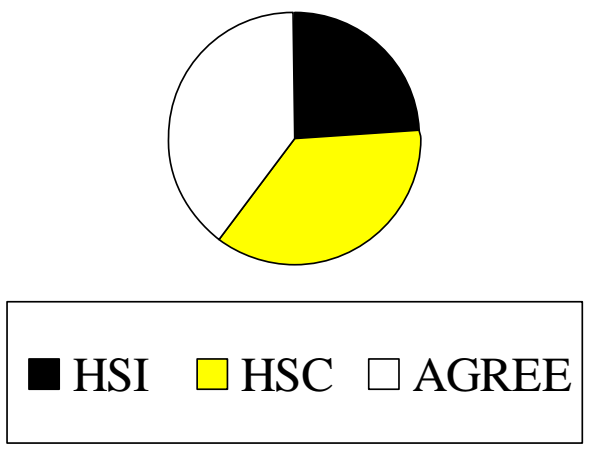

b

Figure 9. Pie charts indicating (a) during what segment of the sampling sequence the majority of Golden-winged Warblers were recorded and (b) the distribution of Golden-winged Warblers within each model type. T1 is the first period in the sequence of a 3-min passive listen, T2 is the second period using the Type I primary song, T3 is the third period in the sequence including a passive listen, T4 is the use of the Type II secondary song and T5 is the final period and passive listen in the sequence. 


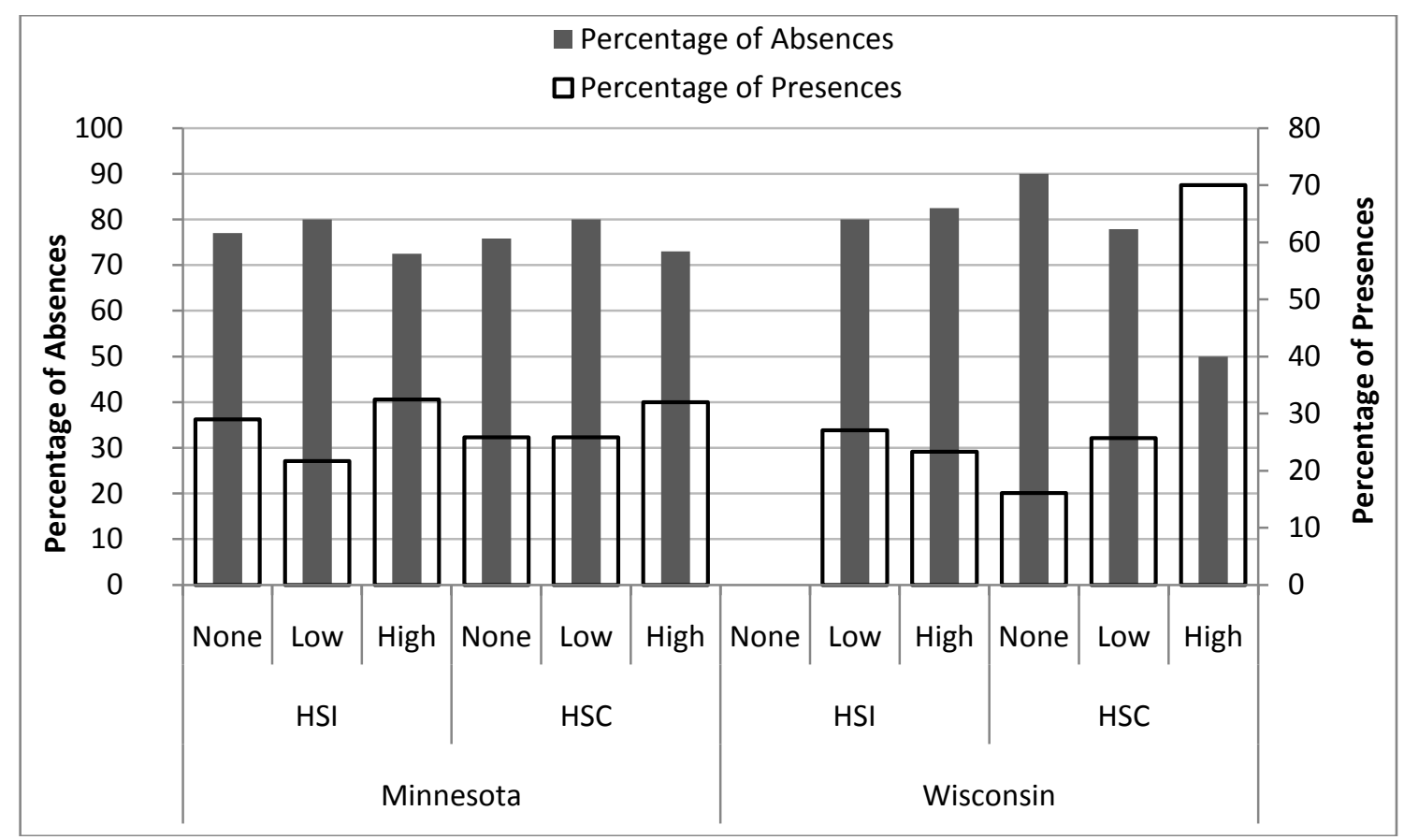

Figure 10. Bar chart showing Golden-winged Warbler responses by state and model. Ideally, observed counts would increase as model prediction increases (none, low, high) and percentage of absences should decrease as model prediction increases. However, the HSC in Wisconsin seems to be the only model performing as expected. Based on values from Table 7. 
Table 1. Variables used by Thogmartin 2007 in the creation of the HSC or (Hierarchical Spatial Count) model for predicting Golden-winged Warbler abundance in Bird Conservation Region 12.

\begin{tabular}{|c|c|}
\hline Variable & Definition \\
\hline Intactness (Heilman 2002) & a measure of forest fragmentation \\
\hline DecidPLAND & $\begin{array}{l}\text { the proportion of deciduous forest } \\
\text { in } 100 \mathrm{~m} \text { buffer around each BBS } \\
\text { route }\end{array}$ \\
\hline Aspen \& Tamarack & $\begin{array}{l}\text { Forest Inventory Analysis (FIA) } \\
\text { data }\end{array}$ \\
\hline TPA12 & $\begin{array}{l}\text { mean number of trees I of } \geq 12 \text { " } \\
\text { dbh at FIA plots within } 1 \mathrm{~km} \text { buffer } \\
\text { of BBS routes }\end{array}$ \\
\hline SPC 45 & specific site productivity classes \\
\hline SSC & $\begin{array}{l}\text { stand size class derived from the } \\
\text { FIA }\end{array}$ \\
\hline SDI & $\begin{array}{l}\text { stand diversity index - derived } \\
\text { from the FIA characterizing } \\
\text { vegetative diversity }\end{array}$ \\
\hline DecidlJI & $\begin{array}{l}\text { interspersion and juxtaposition of } \\
\text { deciduous forest pixels for } 100 \mathrm{~m} \\
\text { buffer around BBS route }\end{array}$ \\
\hline Human & $\begin{array}{l}\text { the proportion of human landcover } \\
\text { classes derived from the National } \\
\text { Landcover Dataset (NLCD) }\end{array}$ \\
\hline Species Richness & $\begin{array}{l}\text { number of species observed in } \\
\text { BBS route }\end{array}$ \\
\hline WET & topographic convergence index \\
\hline
\end{tabular}


Table 2. Nine classification categories used for comparison of the HSC and HSI models. None, represents the absence of Golden-winged Warblers; LOW represents low predicted Golden-winged Warbler abundance; HIGH represents high predicted Golden-winged Warbler abundance.

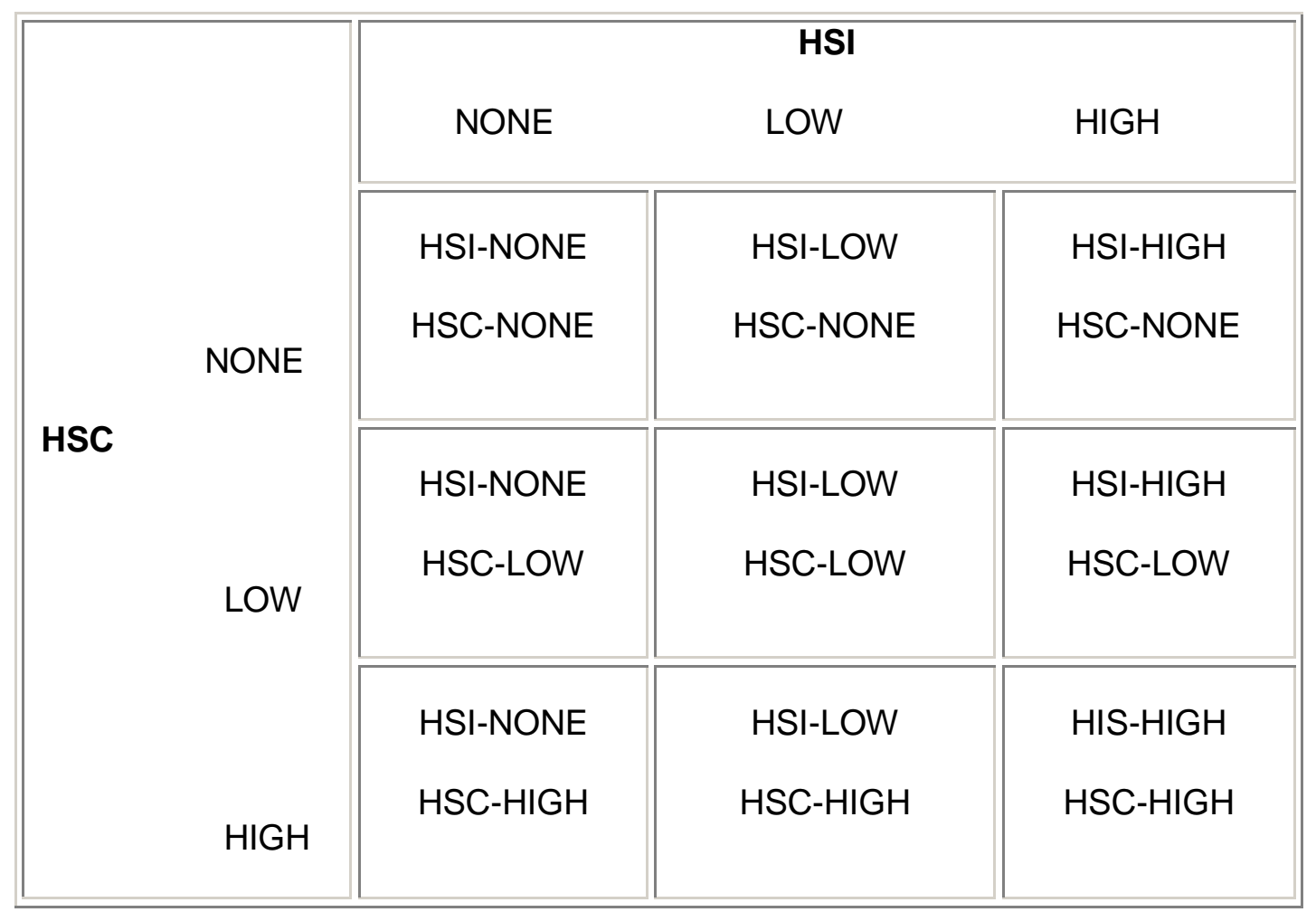


Table 3. A contingency table cross-tabulates observed (actual) presenceabsence data against the models predicted values. Four cells represent four possible outcomes: true positives (a), false positives (b) false negatives (c), and true negatives $(d)$.

\begin{tabular}{|c|c|c|c|}
\hline \multirow[t]{2}{*}{ Predicted Occurrence } & \multicolumn{3}{|c|}{ Observed Occurrence } \\
\hline & Present & Absent & \\
\hline Present & $a$ & $\mathrm{~b}$ & $\begin{array}{c}\text { Positive Predictive } \\
\text { Power }\end{array}$ \\
\hline Absent & c & d & $\begin{array}{c}\text { Negative Predictive } \\
\text { Power }\end{array}$ \\
\hline & Sensitivity & Specificity & \\
\hline
\end{tabular}

Table 4. Contingency tables comparing site-level predictions to observed Golden-winged Warbler occurrence. Each cell represents the total number of sites that were classified as no, low or high according to the model predictions against the actual observed abundance recorded where 'No' $=0$ 'Low'=1 'High'=2+ Golden-winged Warblers per site.

\begin{tabular}{lrrr} 
HSI -Sites & \multicolumn{3}{c}{ Observed } \\
\hline Predicted & No & \multicolumn{1}{c}{ Low } & \multicolumn{1}{c}{ High } \\
\hline No & 77 & 19 & 4 \\
Low & 288 & 57 & 15 \\
High & 185 & 43 & 12 \\
\hline
\end{tabular}

\begin{tabular}{lrrr} 
HSC - Sites & \multicolumn{3}{c}{ Observed } \\
\hline Predicted & \multicolumn{1}{c}{ No } & \multicolumn{1}{c}{ Low } & \multicolumn{1}{l}{ High } \\
\hline No & 253 & 38 & 9 \\
Low & 204 & 46 & 10 \\
High & 93 & 35 & 12 \\
\hline
\end{tabular}


Table 5. This $3 \times 3$ contingency table showing actual Golden-winged Warbler numbers recorded in each of the sample "categories." Each category was identified using Thogmartin's two predictive models "HSI" and "HSC."

\begin{tabular}{|c|c|c|c|}
\hline & & HSI & \\
\hline & NO & LOW & $\mathrm{HIGH}$ \\
\hline & 2 & 21 & 37 \\
\hline NO & & & \\
\hline HSC & 20 & 33 & 15 \\
\hline LOW & 7 & 32 & 16 \\
\hline $\mathrm{HIGH}$ & & & \\
\hline
\end{tabular}


Table 6. Expected values of contingency (an $\mathrm{X}^{\wedge} 2$ statistical test on the data values in Table 5).

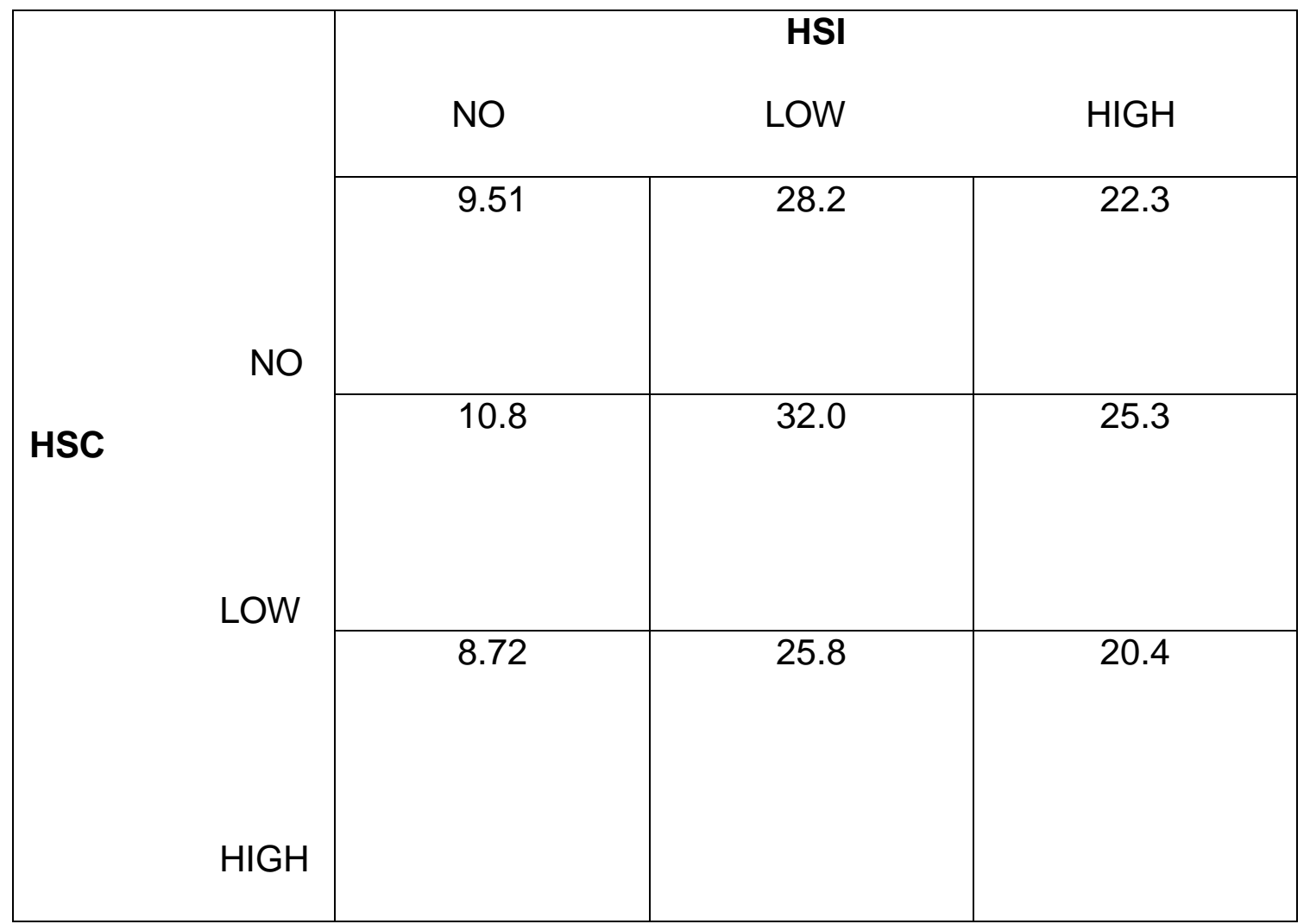


Table 7. Summary of data collected within each state within each model prediction. "Observed" is the total abundance of Golden-winged Warblers observed within each model prediction, "present" represents the number of survey sites at which one or more Golden-winged Warblers were present, "absent" is the number of sites where there were no recorded Golden-winged Warblers, and the "total number of surveys" are the total number of surveys within each model prediction.

\begin{tabular}{|c|c|c|c|c|c|c|}
\hline State & Model & Abundance & Observed & Present & Absent & $\begin{array}{c}\text { Total Number of } \\
\text { Surveys }\end{array}$ \\
\hline \multirow[t]{6}{*}{ Minnesota } & $\mathrm{HSI}$ & None & 29 & 23 & 77 & 100 \\
\hline & & Low & 26 & 24 & 96 & 120 \\
\hline & & High & 39 & 33 & 87 & 120 \\
\hline & HSC & None & 31 & 29 & 91 & 120 \\
\hline & & Low & 31 & 24 & 96 & 120 \\
\hline & & High & 32 & 27 & 73 & 100 \\
\hline \multirow[t]{6}{*}{ Wisconsin } & $\mathrm{HSI}$ & None & 0 & 0 & 0 & 0 \\
\hline & & Low & 65 & 48 & 192 & 240 \\
\hline & & High & 28 & 21 & 99 & 120 \\
\hline & HSC & None & 29 & 18 & 162 & 180 \\
\hline & & Low & 36 & 31 & 109 & 140 \\
\hline & & High & 28 & 20 & 20 & 40 \\
\hline
\end{tabular}

Table 8. Error of commission values were calculated as (number of individuals of GWWA not observed but predicted) / (number of individuals predicted).

\begin{tabular}{|c|c|c|}
\hline State & Model & Error of Commission \\
\hline Minnesota & $\mathrm{HSI}$ & 23 \\
\hline & $\mathrm{HSC}$ & 24.2 \\
\hline Wisconsin & $\mathrm{HSI}$ & - \\
\hline & $\mathrm{HSC}$ & 10 \\
\hline
\end{tabular}


Table 9. Akaike's Criterion values from generalized linear models. After multiple combinations in ' $R$ ', succession repeatedly increase model performance thus was considered in all following combinations.

\begin{tabular}{|c|c|}
\hline Model & AlCc \\
\hline DomShrub, & \\
DomHerb, & \\
DensShrub, & 627.5 \\
Succession & \\
\hline DomShrub, & \\
DomHerb, & \\
DensShrub, & \\
DensTree, & \\
DensHerb, & \\
Succession & 629.5 \\
\hline Surface.Water, & \\
DomShrub, & \\
DomTree, & \\
DomHerb, & \\
DensShrub, & \\
DensTree, & \\
DensHerb, & \\
Succession & \\
\hline Surface.Water, & \\
DomShrub, & \\
DomTree, & \\
DensTree, & \\
Succession & \\
\hline DomShrub, & \\
DomHerb, & \\
Succession & \\
\hline DomShrub, & \\
DomHerb, & \\
DensTree, & \\
Succession & \\
\hline DomShrub, & \\
DomHerb, & \\
DensHerb, & \\
Succession & \\
\hline DomShrub, & \\
DomHerb, & \\
DomTree, & \\
Succession & \\
\hline
\end{tabular}


Appendix A. Data Sheet - Datasheet used during the sampling sequence and for vegetation data.

\section{GWWA Population Survey}

Route\#: Date: Temp: Wind: Cloud:

\section{Bird Data:}

\begin{tabular}{|l|l|l|l|l|l|l|l|l|}
\hline \multicolumn{2}{|l|}{ Point No. } & \multicolumn{2}{|l|}{} & \multicolumn{2}{l|}{} & & \\
\hline Time: \\
Start/End
\end{tabular}

-Please note species and number of individuals (and gender) in each time band as well as distance from road in the second column using the following codes:

Golden-winged Warbler $=$ GWWA Brewster's Warbler $=$ BRWA

Blue-winged Warbler $=$ BWWA $\quad$ Lawrence's Warbler $=$ LAWA

Introgressed $=$ INTG $\quad * *$ Star $(*)$ for visual confirmation 


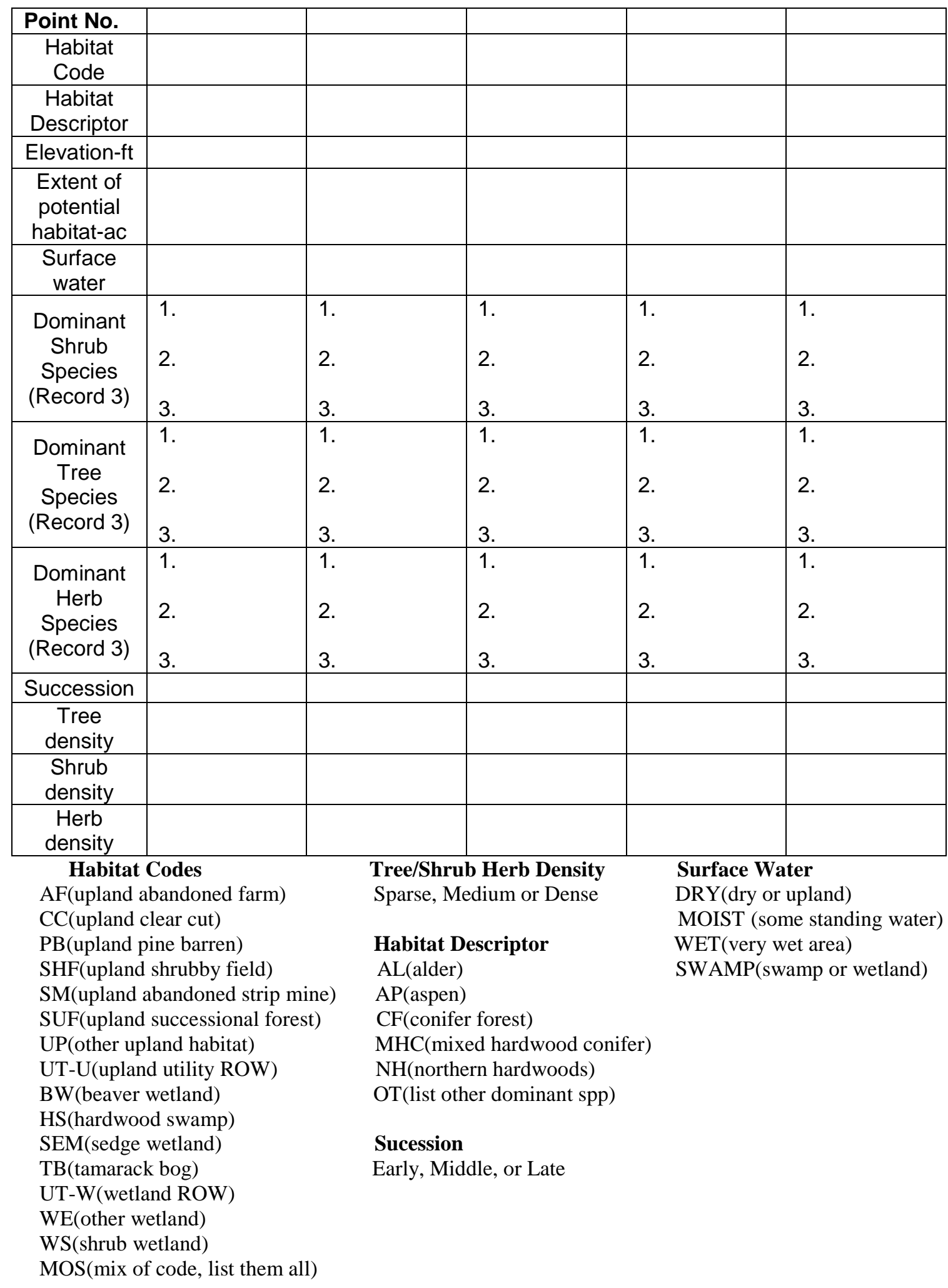

